\title{
Visual Perception of Children and their Pictorial Repertoire
}

\author{
Bozena Supsakova \\ Comenius University, Faculty of Education, Bratislava, Slovakia
}

\begin{abstract}
Art is universal. It has neither time nor territorial dimension. Similarly, the child's artistic expression has become the means of cognition and communication between children of all cultures; it links children all over the world. The child's artistic expression comprises creative exploration and selfreflection. Children learn to establish and gradually extend their perception of new phenomena and new processes, namely by means of differentiation of picture signs and their renaming. Each individual observes the world (the object) with their own eyes and expresses it by their own artistic (sign) means. Nowadays, these form the space for denotation of new quality; they form new pictures and they literally teach - how to see differently. Thus, they form the right habits. It implies that drawing, as well as other expressive art-concerned activities comprise concentration and forming of self-discipline. Artistic means help the adults to get to know much more about the child's ontogenesis, about their intellectual and emotional potential. They form conditions for learning our own and foreign culture. They also provide space for active, amusing and meaningful work.
\end{abstract}

\section{Introduction}

A long-term research, carried out in recent years, authorises us to state that any creative fine art activity of the child is influenced by the environment in which they live. On the lowest level - the microsystem - it is predominantly the family, classmates and school, whereas each of these factors affects the child individually, and influences them. Another hierarchical level is the mezzo-system. It represents the system of inter-relationships and links to school, family and classmates, their synergetic (progressive and regressive) effect on the child's individuality and simultaneously on their creation. A number of child's drawings in this publication serve the adequate evidence. Above this level, there is the exosystem which influences the child indirectly, vicariously, namely by new visual media, by the existing economical conditions and the political system of society. The outer layer which surrounds and vicariously forms the child is the macro-system. It reflects general cultural stances of the child, i.e. spiritual values, culture, both national and regional culture and traditions.

\section{Visual Media and Imagination}

We stated that the child's artistic expression is influenced at the level of the micro-system, mezzosystem, exo-system and macro-system. Nowadays, we live in the era of the electronic media and communication (television, computers, internet, multimedia, play stations, mobile telephones, and virtual world on the internet). Their coverage and new forms distinctly interfere with our everyday life and they start to influence and perhaps to change the long-term fixed habits of acquiring information, abilities, skills, and above that the child's artistic expression. Therefore we are going to pay more attention to this topic. In the broader sense of the word "multi-medial" and "multicultural" communication, audio-visual media included, in nowadays conditions can reach to the mind's development. This can be significant especially at younger generation.

Pedagogues, psychologists, sociologists and others who deeply study the issue of ontogenesis of the child and the child's artistic expression ask the question: To what extent do the nowadays cultural and communication phenomena affect the mind's development, the learning process and the presentation of knowledge?

Television, film, video and the most recently the internet and social networks (Facebook, Youtube, etc.) belong to the visual electronic media of mass coverage which attract not only adults but also children. The way of presenting the information and on the other hand the direct "consumption" of the programs is similar to reality. We are going to consider what role, actually, the electronic media play in the learning process, in acquisition of new information, when and to what extent they influence the child's artistic expression. In the following lines we will also pay attention to the process of development of the picture view and the art presentation in the environment of nowadays visual media. [7] [8] [9].

The fact is that nowadays there is practically no relevant research aimed at the influence of the television pictures, computer signs on the life of a child, multimedia and internet on-line games included. Although the numerous explanations have been publicised, they are not scientifically documented. Nowadays, it is indisputable that many children, if not majority, spend a lot of time in front of the TV screen, the computer monitor or the play station console. In fact, it is much more hours in comparison with the generation of twenty, thirty or 
forty years ago. However, we do not have any relevant indicators on the influence of the visual media from the past. Therefore it is difficult to make comparison with nowadays.

The family environment contributes to the abovementioned to a large extent. In many families, the visual media has become an idol, the centre of the family events. The TV programmes substitute the family communication. The passive reception of information, among others, is a disincentive to cognitive development of a child. The importance and ability of learning to listen to the others is trailing off, and the imagination is weakened. In the family discussions, the ability of active solving of concrete situations is not developed, and there are rare discussions on the future, experience and emotions. Many parents tend to underestimate and simplify the problem instead of "diverting" the habits, or better to say annoying habits, from the computer signs or TV program to active communication and active reception of information.

\section{Virtual Perception and Experience}

Our empiric knowledge in the recent years is that the computer games and TV programmes lead to passive perception and passive reception of information. A swift movement, dynamics of events and light shows influence the child in the broader sense. The influence concerns the content and the form of the child's artistic expression. These factors inhibit concentration and eventually also the ability to hear. It is reflected at school, namely that the children expect the teacher to serve them with the picture instruction prior to the verbal one.

For a culturally literate person of nowadays, accepting and (re)producing of cultural values in their broader sense, including reading, writing or existing in semantic space is of great importance. From this point, notable findings have been recorded by the researchers in their four-year foreign research aimed at correlation, the relation between the passive perception of a TV programme and reading. It shows that this media has a negative influence on development of reading, namely the type where closer comprehension of the text or of the illustrated picture is required. Excessive passive perception of TV programmes and passive reception of information deprives of the pleasure from reading; what is much more important is the fact that the reader's ability is underdeveloped. Above that, at children who sooner or later succumb to the style and regularities of TV pictures - schematic, shortcutmodels of problem-solving and looking for simple answers, there is a negative attitude formed. We can positively state that the passive visual perception without verbal language is simple, in its essence, and it does not involve almost any activity. There is no wonder - the children approximately to nine years of age are not that intellectually and emotionally mature to be sufficiently critical and able to closely differentiate importance of the story. "Exactly at this age, there is, on a wider scale, decentration of thinking developed, and children gradually start being able to compare the plot of the story with their own inner standards and norms of behaviour." [17]

\subsection{Passivity of Brain}

A part of experts shows their worries concerning the fact that the visual media of nowadays suppress active learning, and therefore they lower the ability of active reception of information. This way, the concentration and abilities of children are inhibited. Let's illustrate this in the example: a child, without any selection, perceives the TV programmes or computer games on a passive and long-term basis. These are mostly action-like, dynamic, so they are very attractive for young people. On the other hand, they are without any deeper plot coherence. Predominantly, they are not helpful in personal development. If we task the student to read the text, to "read" the picture or give them any other creative task - they suddenly become disoriented, unable to think straight, and their concentration is very low. (If the child is to learn well and positively solve some concrete situations, it requires active approach, engagement, persistence and creativity.) Failure, exactly at this crucial point, causes many of the children not to be able to learn, they accept the new information with difficulties, their thinking, imagination and fantasy is developed more slowly.

Many adults intuitively sense that even at this simple example we can state that: a lot of time spent in front of a TV screen or another visual electronic media is the main cause why the children show tendencies to passive learning and passive perception of information; though majority of parents are not aware enough of the danger. This fact is going to be revealed soon, namely in the situations where the children give up too easily at the first obstacle and they are not strong enough concerning their personality. We forgot to teach the children! We teach externally, not internally. We form the child's personality, whose model of behaviour is influenced by the external inputs, show business with its pop stars and extravagance. [2]

\subsection{Visual Picture and Neurological Perception}

Many experts in the field of fine-art theory, even today, put forward the question on whether and to what extent the visual media, the visual pictures and inputs included can change, eventually influence the child's brain structure and learning. At present, there are a lot of discussions on this topic but the outcomes, so far, are not unambiguous. Some effects of the influence are yet shown, and therefore we can expressly state that the part of TV programmes, 
video programmes and action computer games artificially "manipulate" the brain. They affect the models of behaviour. It is done with the aim to attract certain attention by means of visual and auditory inputs and the changes like a quick and dynamic switch of the scene, action of the plot or special effects. The final aim is to induce neurological passivity and disturb the balance. At present, there are many ways how to make the brain active in the desired and strictly given direction. For the child there is a moment of surprise, bright colours, swift movement and a sudden sound. These are the elements which current advertising (conception of the "brain wash") as well as TV programmes for children and adults count on. Exactly these programmes introduce the habits how to, through certain input effects, keep the attention and concentration of the viewer. Permanent repetition of certain mottos and slogans forms and influences the behaviour (at the adults, the most frequently shopping habits) of the addressee.

And what is the situation concerning the videogames, computer games or on-line games on the internet like? Although there do not exist any relevant researches, we can positively state that: they are designed in a way that they promise certain and concrete solutions to the player. They are programmed with a certain degree of difficulty, and these so-called levels have to be accomplished by the player in order to continue any further. These motivate the human brain to the task-solving and simultaneously to the obstacle-overcoming. [14]. Thus each of the successful or unsuccessful effort of the individual is immediately evaluated, and the machine becomes the so-called personal tutor. The tutor gives advice and at the same time encourages towards the achievement of aim. The advancements in the play cause the feeling of self-satisfaction of the player, bring them strength and self-confidence. The child comes to the feeling that s/he keeps something of the social importance under control. This can afterward compensate their frustration from the real life when they themselves feel that the things do not go the right way.

Computer games and videogames require the player's attention. The success, above all, assures the series of the following right decisions. So far, there is no methodology to offer a worked-out system on how to transfer this degree of attention to other kinds of study. Linda Siegel, the author of many scientific works from the area of school education, admits this kind of possibility. According to her, a greater advancement could be achieved in the field of visual holistic perception, prior to the field of rational thinking. She is not that convinced whether electronic games develop the kind of abilities, such as creation and decision taking. [2]. I also watched children playing games on the computer and playstation console. I was curious whether they make their decisions on the rational basis or if these are momentary, random decisions. I was interested if there is a system of rules in their minds or if it is an intuitive reaction. It seems that their reactions are guided; yet it is not clear what level of management control the children apply. If this is the intuitive decision-making - is it thinking at all? There is no clear answer to these questions even in the scientific environment. It is subject to further exploration [16].

\subsection{Problem of Transmission, Transfer}

A part of experts assume that more inconvenient environment than the TV picture is formed by the videogames, various play-station consoles and computer games. Can there be an educational effect of the action electronic game during which the child fights for victory in a fantastic virtual micro-world? Is there developed and cultivated seeing as the main source of collecting information about the surrounding world, artistic world or the life of other people? If the abovementioned was true, this reality could bring a number of information and non-verbal means concerning organisation of thinking. Visual cognition and communication in various forms requires, therefore, adequate proportional development and cultivating of visuality.

Is the picture imagination, child's creativity, cognition and comprehension of artistic expression developed hand-in-hand with distinct influence on social, ethic and aesthetic dispositions? To put it differently - does the abovementioned develop and cultivate the emotional intelligence? Do not the TV picture and computer simulation create a barrier, as they differ from the natural game and interpersonal interaction? Can children learn the strategies on general problem solving in this way or do they lose their own ability to think, create and artistically express their opinion?

From this point, the key solution at assessing either positive or negative influence is the problem of transmission, transfer. It means, the kind of intellectual and emotional "heritage" the child can take from the already mentioned, and particularly how much of that they can transfer and use in other spiritual activities. Do the mentioned activities at least contribute to the child's personal development? Exactly here we can see the core of the problem which can be formed in a simplified way, like this: there is very little from the passively acquired knowledge, information, abilities and finally also skills to be transferred to other activities.

We could speculate that the multimedia computer games or on-line internet games located to space and requiring the space orientation from the child and their swift reaction to inputs could positively influence, for example, the speed of reading, visual perception and this way develop and cultivate seeing. We also could speculate that simultaneously with learning to program the software, the children also learn how to think critically. Our opinion is that it is 
not exactly the case. The reason is simple: we train the brain with our activities for only one limited area. There arises the question: How, and is it yet possible to transfer the already learned and acquired to another area of human activity?

When we teach the child to "read" the picture, artistically portray or graphically record the story, it does not imply they are able to positively apply this ability in the subject of history. When the child, through the picture media, passively perceives a lot of visual inputs, it does not yet mean that they can "read" the picture. The brain has millions of cell networks, and it is not possible to simply state how the related transfers work. Many foreign researches acknowledge that the training of the eye itself through the schemes and drafts, in the principle, has a small effect not only on the reading ability, but mainly on developing and forming the child's personality. Similarly, listening to music does not lead to better auditory abilities which could be utilised perhaps at language learning. The words and melodies proceed in completely different memory cell networks. Identically, there is no proof that the visual simulation as a consequence of passive perception of TV pictures or other passive picture inputs contributes to development and cultivation of visuality in other areas of human activity.

Artificial encouraging, stimulating the brain centres cannot be overestimated and simply cannot substitute the active process. Any strong visual percept from the media cannot substitute expressive artistic perception or child's artistic creation itself which is a priori based on activity. Similarly, active perception and reading of an artistic artefact or the child's artistic performance cannot be substituted. These stimuli certainly do not increase efficiency of the learning process, and finally they are not helpful at school where there is very different, much calmer atmosphere. We could therefore admit the negative effect on the child who, under the influence of the visual media, gets used to the stimuli - and subconsciously expects them at school. It results in inhibited activity of the child.

We attain the knowledge that predominantly the text-reading, active perception of visual pictures, i.e. reading the pictures, artistic creation (also in visual media) is the best method leading to development of seeing and visual perception, to development of communication.

This kind of guidance (upbringing) stimulates the research process, the feedback and searching for the answers which form the ground for familiarization with fine art. It enables the child to think, compare, make up with their own consideration and develop their cognition and communication in this way. The old "modus operandi" is always there: The longer and more thoroughly we watch, "read" or study the artistic performance, the more it can reveal. It is approved that the children usually study the artistic artefacts systematically. They view the whole as a set of details among which there exist certain relations. Thus, they are aware of some analysis and also synthesis. Different stages of cognition, different views (one sees it his own way, another has a different opinion) can, in the end, complement each other. The range of possible interpretations of the artistic performance referring to another artworks, art-related objects and information concerned definitely affect the organisation of whole viewer's mind. It also develops the viewer's cognition, their skills and abilities. Insufficiency of definite answers in the field of fine art leads to assumptions (What did the author have in mind?) or in better case - to collecting of creditable and believable information.

From the abovementioned, it is obvious that one group of children will be satisfied with the given degree of cognition, and will be satisfied with the answer to the question on what the author had in mind. Second group of children will look for more evidence to "terminate the investigation" aimed at true incentives and intentions of the author and his artistic performance, to gradually receive the answers to questions on the author's imagination, their style of creation, artistic language or artistic speech. This group wants to know more about the author - who the author of the artistic performance is, when and why it was produced. The aim is to constructively and actively work on themselves, on increasing their own cognition - by perception of adequate stimuli through the process of reflection their own perception and cognition gradually reach this aim and receive the answers to the questions: What exactly does the artistic performance represent? How was it created? Who made it? When? Where? Who for? What for? Etc. It stimulates children to the artistic utterance and their own artistic creation, even through visual media.

The past can be understood as the inspiring background for a new creation. History serves us with valuable knowledge on how the artists worked, what inspired them and what they fought with or what expressive means they used. However, the dynamic present and close future in the name of information society brings us new challenges, new topics, new relations which cannot be exhaustively portrayed using the classical artistic means. It is necessary to stimulate the children to artistic utterance and towards their own artistic production, even using the new visual media, such as computers and the internet. Creative approach and using of these possibilities bring down the already acquired, very precisely curbed way of expression, and actively draw the child into the areas which were accessible for previous generations without special education.

In the process of creation where serious and artistically rewarding game is concerned, the artrelated problems are solved and the art-concerned answers are sought. The artist sometimes plays, sometimes artistically works, thinks, infers, searches 
for artistic possibilities of solutions, associations of thoughts and creates their own artistic language. They try to divert from the unusual schemes of thinking, not to understand anything as firm, unchanged, and yet to keep their own opinions, their own thinking. The heart of creation, as far as it pays off, is in finding something new that represents enrichment of culture and society. The creation, simultaneously, is the target category of art which is partially developed by the means of such a medium the computer. The characteristic feature of creation is originality, the originality which is socially required, not the originality at all risks; next, there belongs original fantasy, guided by certain socially valuable aims - the creative fantasy. This way understood creation, socially required not only in the artistic and scientific creation but also in routine-life situations, is considered the most valuable characteristics of personality. The reason is that it forms the space for autonomy and self-realisation of each individual. From this viewpoint, the priority task of the school and education is not the method of implementing the electronic media to education but the issue of introducing the children to the world of spiritual values through the already existing anthropologic values of childhood and mankind using all moderate means of nowadays.

There is the child who draws, paints, creates spatial objects, and learns to see. It is a specific, original learning process which is in permanent progress, whereas the crucial factor is quality of seeing. Therefore it is an active way of reception of information requiring the individual's own thinking but also implementation of principles of creation and fantasy. If the child passively spends a lot of time on videogames or other visual media instead of active reception of information in the process of creation, it inevitably does not contribute to forming of their personality. This fact is revealed positively or negatively much later, i.e. during puberty or adolescence when the young person is expected to think critically and reason abstractly. Young brain should have the tendency to be developed towards higher horizon. The neurological paths should not be ameliorated only in one specific area. This point is of a great importance for good reasoning, healthy thinking as well as for development of imagination.

\subsection{Impact of New Technologies}

A new element which we have observed at young authors is preference of graphic symbols to verbal expression. It is a result of commencement of new technologies (e-mails, chat, sms messaging) which is liked mostly by young people. These forms of mutual contact, with regard to technological nature, use short expressions through abbreviations even signs (it saves time, fees for connection and transfer of messages and alike), and thereby makes the used terminology expressly poorer - there is a lack of interjections, extended sentences and similar. Instead of that, there are graphic symbols in the form of Smiley faces through which the feelings of joy, grief or surprise are expressed in a special way.

To express the feeling of joy through art, children used the symbols of candies, gifts and alike very often. Many of them were happy with the symbol of Smiley face; today very frequent in short messages and any electronic messages. Children have explained that the Smiley face is ok because it makes communication faster, saves written and spoken word. And most of all it is understandable for everyone, especially when appearing at the end of a sentence. In the drawn form it looks nice, it is a symbol of positive message, mood, energy, similarly like on the display of mobile phone.

\section{New Possibilities for Visual Recording}

The article presents partial result from our research (also within VEGA 1/0158/08 Visual symbol, similarities and differences in visual figurative expression of children and youth) also. The acquired knowledge allow us to accept the following generalization: children and young people today work on computer daily, nearly all of them have a mobile phone and the internet is a source of their entertainment, information and means of communication. Every day they collect new experiences, make real and virtual contacts. There are new possibilities for visual recording of reality but also for (self) presentation here. At the same time there is an opportunity to enter the world in which what is the most important are the sound brand marks, good image and fashion trends. Young people prefer a favourite advertisement, media, brand mark things, adrenalin activities, they have courageous plans and ambitions, they can travel, they want to see and know a lot. They want to be carefree, happy, and single and they want to have money. It is evident that the world of the present day young generation is different, their opportunities are being extended and they are developing.

Nowadays there is a publicly placed question if and to what extent the visual media, and thus the visual pictures and impressions, can change or influence the child's brain structure and learning. Nevertheless, some effects of the influence are shown and therefore we may state that part of the television programmes, video programmes and action computer games "manipulate" artificially with the brain and influence the behaviour patterns. That is done with the intention to draw certain level of attention through visual and audible perturbations and such changes as rapid and dynamic change of scene, action in the story or stunt effects and eventually, to induce neurological passivity and disturb balance. Now there are several ways how to force the brain to be activated in the required and exactly stated direction. The moment of surprise, 
sharp colours, rapid movement and quick sound is enough for a child. All in all, current advertisement (concept of "massaging the brains") takes this into consideration, as well as television programmes for children and adults. Exactly these teach the habits how to hold attention and concentration of receiver through certain perturbation effects. To form and influence receiver's behaviour (at adults the most often shopping) by ongoing repetition of certain words and slogans. According to our survey, approximately 50 percent of 9 to 11 year old children said they watched TV programmes, including advertisement daily. They prefer visual perception to auditory or emotional. Approximately 90 percent of children are fascinated most of all by colourfulness of TV picture, after that it is movement and spoken word. Therefore their replies read: "I do not have to read." "I do not have to walk in the street." "I do not have to watch if I do not feel like, I only listen." In this regard, the Canadian medial theoretician and sociologist Herbert Marshall McLuhan frequently expressed himself to the issues of the task and influence of the up-to-date media on man, especially on children. In some cases he had very categorical opinions. In his view, all the media themselves and irrespective of the mission they send have a significant influence on man and society. “...only a few brains can survive the intellectual torture of our educational system. The mosaic picture of the TV screen creates the profoundly pulling present and simultaneity in children's lives, and under their influence they despise difficult visual aims of the traditional education as something unreal and inconsiderable. Another vital problem is that too much is taught at our schools by traditional analytical method: and we are in the age of information overloading. The only way how to reach the state that the school is not a prison without grilles is to start with completely new techniques and values." [10]

\section{Conclusion}

Traditional aiming of research at graphic production, and especially drawing, so far has limited the space for discussion on ontogenetic development in the child's artistic expression. Some researchers, aware of this fact, start to use closer denotations in their publicised works. For example, there is development of picture imagination or a graphic symbol, which according to the technical literature, comprises all symbolizing or substituting qualities having the graphic form in the shape of a line, surface or system of graphic traces. The graphic symbol situated between the word and picture is irreplaceable. Their common feature is the graphic form but semantic value and concrete shapes are distinctly different.

The process of creation and the artistic product, as well as our further empiric knowledge show us that the child's artistic expression of nowadays is not only a demonstration of what the authors know and see in their surroundings. Knowledge that the child's artistic expression is bound to the system of symbols is important. Children literally explore and create various systems of symbols which simultaneously enable them to create their own vision of the portrayed world. As we are persuaded by some of the examples in this publication, in the child's artistic expression, their own graphic logic prevails. At an early age, children gain the ability to use the graphic language. They simultaneously develop different possibilities of expression and a different visual language.

Today, it is evident that the child's artistic expression is influenced in the socio-cultural context, multi-medially and multi-culturally. It is changed also thanks to current trends in the fine arts. Children do not counter these changes, they gradually use new means of expression, change the content and the way of portraying. As their artistic expression is influenced by the environment and at different levels, it is diverse and multilateral. It is quite difficult to speak about strictly defined evolution concept of the child's artistic expression. In the ontogenetic principle, linearly understood concept of the development of the picture creation seems to be insufficient in the present day conditions. It is perhaps indicated by the content of the publication together with many illustrations. The concept of the child's artistic expression is more acceptable as the concept of the "open structure" because the children at the same time develop different possibilities of expression together with the visual language.

Contemporary process of the picture imagination has to be viewed as a reflection of a civilised society. Today, we live in the era of the electronic media and instruments (television, computers, Internet, multimedia, playing consoles, mobile telephones) which by their impact and new forms exert influence in a significant manner on our everyday life and begin to influence, or, change usual habits of acquiring information, abilities and skills as well as the graphic expression of children. In the broader sense of the word the multidisciplinary and multicultural communication and the visual media have at present an impact on the development of mind, which can be significant especially in children of the younger generation. There is, however, no doubt that many children, if not the majority of them, spend a lot of time either in front of the television's screen or in front of the computer's monitor, or with a playing console. This really represents much more hours in comparison with the generation twenty, thirty or forty years ago.

But today it is evident that the children with better school results are not interested so much in the visual perception of the television picture and electronic games as the average or below average 
children. It is also evident that many children deprive themselves in a very cruel way of time that could be devoted to important activities and active reception of information. The passive reception of information is, among other things, a brake of the cognitive development of a child, the sense and the ability to learn to listen to the others disappear, the imagination weakens. The children's drawings document that in the family discussions the ability e.g. to solve actively concrete situations is not being developed, the future, experience and emotions are discussed very little. Many parents instead of literally ,redirecting“ these habits, or better said bad habits from the computer signs or television screen to the active communication and active reception of information often underestimate or simplify this problem.

\section{References}

[1] Davis, J. (1997). The „U“ and the wheel of „C“: development and devaluation of graphic symbolization and the cognitive approach at the Harvard Project Zero. In: A. M. Kindler (Ed.) Child development in art. Reston, NAEA, 1997, pp. 45-58.

[2] Healy, J.M. (1999). Endangered Minds. New York.

[3] Goodman, N. (2007). Jazyky umění. Nástin teorie symboli. Praha : Academia.

[4] Jirák, J., Köpplová, B. (2007). Média a spoločnost'. Praha : Portál.

[5] Kindler, A. M. (2000). Drawing development through the lenses of age and culture. Paper presented at the 30th Annual Meeting of the Jean Piaget Society, Montreal : Canada.

[6] Lester, P. M. (2010). Visual Communication. Images with Messages. California Thomson Wadsworth 4th edition.

[7] Livingstone, S. (2002). Young People and New media: Childhood and Changing Media Environment. London : SAGE.

[8] Livingstone, S. (2008a). Engaging with media - a matter of literacy? Communication, Culture and Critique, $1(1)$, pp. 51-62.

[9] Livingstone, S. and Haddon, L. (2008). Risky experiences for European children online: Charting research strengths and research gaps. Children and Society, 22, pp. 314-323.

[10] McLuhan, M. (2008). A man, electronic media and culture Brno: Jota, (p. 262).
[11] Munro, E. (2008). Effective Child Protection. London : SAGE.

[12] Palmer, S. (2007). Toxic childhood: How to Modern World is Damaging Our Children and what we can do about it. London : SAGE.

[13] Pink, D. H. (2008). Úplne nová mysl. Praha : Ideál.

[14] Shaffer, D., Squire K., Halverson, R. and Gee, J. (2005). Video games and future of learning. Phi Delta Kappan 87 (2), pp. 104-111.

[15] Šupšáková, B. (2009). Child's creative expression through fine art. Ljubljana : Debora 2009.

[16] Šupšáková, B., Tacol T., Čerkes, B. (2007). Art Education: retrospectives, perspectives, alternatives. Ljubljana : Debora.

[17] Šupšáková, B. a kol. (2004). Vizuálna kultúra a umenie $v$ škole. Nové myšlienky a prístupy. Bratislava : Digit.

[18] Šupšáková, B. (2013). Detský výtvarný prejav: od čmáraníc k obrazom a ich významom. Bratislava : DOLIS.

[16] Šupšáková, B. et al. (2014). The Media Literacy of Children and Young People. Bratislava : IRIS.

[17] Vágnerová, M. (1999). Vývojová psychologie. Praha : Karolinum. 